\title{
Research on the Evaluation System for the Project-Based Curriculum
}

\author{
Xiaojuan Sun ${ }^{1, \text { a }}$, Jin $\mathrm{Wu}^{1, \mathrm{~b}}$ \\ ${ }^{1}$ Department of Information Engineering, Liaoning Forestry Vocational and Technical College, \\ Shenyang, 110101, China
}

aemail: Sunxiaojuan8@163.com, bemail:Wuzhixuan_2010@163.com

Keywords: Project-based teaching; process evaluation; evaluation system

\begin{abstract}
This paper proposed an entire new evaluation system which is a combination of theory and practice through the project-based curriculum of the Website Design. This evaluation system plays an important role on fulfilling the curriculum target, advancing the curriculum reform and taking exams to promote learning.
\end{abstract}

Along with the building of harmonious socialist society, people of different social classes pay more attention to higher vocational education. More and more senior middle school students choose higher vocational education as new starting points of their lives. It is an important issue in teaching reform of higher vocational colleges: how can the students apply what they have learned in future career. This issue comes from students' poor practice ability. Moreover, they can not utilize knowledge they have acquire sufficiently. Nor can they analyze and solve problems independently. There is no work experience, nor are they once in project development.

In project-based teaching, students participate in project development. Teachers divide a project into several sessions and demonstrate for students. Discussions about projects are organized among students to help their learning. Teaching processes are completed along with the completion of projects. Students' studying is evaluated by the development of projects.

Teaching content was organized according to tasks of projects. Students realized the content is related to projects. Moreover, barely theory is not enough; the theory must be combined with practice to complete projects. Project-based teaching surpassed old methods. Students acquired knowledge by solving real problems and they studied actively. Their ability of practice and solving real problems was improved obviously.

In the past, evaluation on students focused barely on the results.

Assessing section is consisted of process assessing and result assessing in project-based teaching. Comprehensive and accurate assessment was given to students focusing students' entire designing work. It focused not only students' skills and creativity, but also the cooperation with each other. At the end of each task, there will be a self-assessment and a group assessment. Teachers will give comprehensive assessment according to skill assessment, self-assessment and group assessment. Students can reconsider there practice skill and realize there weak by self-assessment. The group assessment helps students to view problems from different aspects or extent. It can enhance cooperation and interaction. Teachers' evaluation can guide students' development and give instructions for students' improvement. Project-based teaching stresses process evaluation and feed back for theoretically and practically. It pays attention to comprehensive development of students' quality and it is student-oriented. Thus it is an effective way to appraise developmental teaching and it can guide students' learning.

The process of doing projects is the process of researching and exploring for students. Summation and assess are fairly important. Studying effects should be summed up and assessed according to the completion of projects by students. The exam can be classified into three levels. First, teachers examine the group projects. Second, members evaluate each other according to the attribution in their own groups. Third, each student carried on self-evaluation. Learning effects of students were assessed and summed up according to the evaluation of three levels above.

Website Design is the model course of the first batch of project-based teaching reform in our college. The reform of Website Production course has gained great effect on the integral design, 
unit design and class teaching effects. However, the problem is how to evaluate the extent of students' learning.

The traditional assessment of vocational school's course is the final assessment, according to the method which only based on final test. Under this system, most students can not correct their learning attitude and study knowledge step by step. So as the teachers. The teachers can not know clearly about the extent of students' learning. Therefore, it is unscientific and unilateral to evaluate students only by the examination score[1].

\section{Methods on Curriculum Assessment}

The teaching patterns should adapt to the cultivation applied and technical talents so as the course examination should adapt to the teaching pattern. Meanwhile, formed in the teaching process, “teaching product” should also represent students' ability of technology application and students' comprehensive quality.

After curriculum reform practice, Our university open course can be divided into five types, two kinds of process, Although we have different models of course assessment, the "teaching product" should be the important basis of students' ability and quality, and the final test should be the assistant form. The proportion as followed:

Usual assessment(70): process assessment (30), teaching project assessment (20), teaching product assessment (20); Final assessment (30), Evaluating the comprehensive ability of website design.

The ability of technology application and career quality is the main point in the usual assessment. Teaching products (the products formed in the process of teaching and based on the vocational product criteria) assessment evaluates the students' job ability and quality through product scale, product quality and product efficiency. One- hundred-minute final test focuses on the crucial theory on objects laws, job principles and so on of professional work. The scores that the students finally got is based on usual assessment and the final test. The form of the exam is based on the goal of the course.

\section{The Contents And Proportion Of The Assessment}

Usual assessment

Process assessment accounts for 30 scores. Working security accounts for 1 score (If there is no damage of equipments and no personal injury in the class, the student would get one score. If the student does not obey the operation standard or causes damage of equipments and personal injury, he will get zero score in this part. If the students break the operation standards for three times or leads to grievous bodily harm, his final score will be zero score.). Working discipline accounts for 4 scores (Full time class and full attendance will get you 4 scores. If you are absent from the class once, you will be reduce one score. If the class time you lack of is over $5 \%$ of the whole class time, you will get zero score in the working principle part. If the class time you lack of is over $30 \%$ of the whole class time, you will get 0 scores in your final score ).

Cooperative ability accounts for 5 scores. (the member of the team give scores to each other, and take the average score as the score in the cooperative ability part.)

Teaching project assessments accounts for 20 scores. (according to the quality of the project that students finished by themselves). Assessment project one: Making the homepage of the Timber and Engineering Department(10), assessment project two: Making the homepage of Housekeeping Department (10) .

Teaching products assessment accounts for 20 scores. On-class products accounts for 30 scores and out-of class products accounts for 10 scores. The on-class product is to design the portal for our college and the out-of-class product is to design personal homepage.

Final test assessment

The final exam is to test the important knowledge of designing the website. The test will be taken from the question bank. 


\section{The Framework Of The Examination System}

\section{Examination arrangement}

Examination arrangement of the teaching project of the usual time

Assessment 1: Making homepage of the Timber and Engineering Department by using Dreamweaver which accounts for ten scores. Students should do it all by themselves and they will costs four lessons to finished it. The computers that students used to have a test should be with DW, PS software, the firefox browser should be newer than IE6.0. There will be three proctors when students have an examination.

Assessment 2: Making the homepage of Housekeeping Department by using div + css which accounts for ten scores. Students should do it all by themselves and they will costs six lessons to finished it. The computers that students used to have a test should be with DW, PS software, the firefox browser should be newer than IE6.0. There will be three proctors when students have an examination.

After the assessment, students hand over the answers through the website, and the teachings will give the scores according to the standard answer.

Arrangement of teaching products assessment

Product 1: Making portal site for our college accounts for thirty scores.

Product 2: Making personal homepage accounts for ten scores.

The assessment of the teaching product costs four lessons. Students should show their products by PPT, through which they should show their making process, technical points, difficulties and solutions. The teachers will give scores according to the following chart.

Arrangement for the important theory examination

Important theory 1: Establishment and management of the website platform accounts for fifteen scores.

Important theory 2: Criteria and norm of the website development accounts for twenty scores.

Important theory 3: Basic knowledge of HTML accounts for 25 scores.

Important theory 4: Basic knowledge of Dreamweaver accounts for 25 scores.

Important theory 5: Basic knowledge of ASP accounts for 15 scores.

Choice base and grade standard of assessment part

Projects selecting is the key issue, Project-based teaching is adopted in the Website Design teaching. The entire teaching is consisting of real projects. Teachers select projects according to teaching content. Teaching process is fixed when projects are determined. Students get knowledge in this course by completing projects. Thus the selecting of projects is essential. The essence of tasks should be thoroughly recognized. Trend of the Website Design and social need should be studied, as well as students' basic knowledge and characteristics. Teachers should choose what can interest students. Second, the relationship between new knowledge and old one should be noticed. Knowledge and skill are accumulated step by step, thus the joints of new and old knowledge should be considered. Acquired knowledge should be reviewed when learning new. Thirdly, the difference among students should be aware of. They must all get something. There must be tasks of various difficulties.

The teaching content of Website Design can be divided into three parts: designing website by using Dreamweaver, designing website by using Div+Css and ASP. Designing website by using Dreamweaver accounts for $30 \%$ of the whole lessons, designing website by using Div+Css for $60 \%$ and ASP for $10 \%$. From the proportion, we know that the first two parts are the important parts, thus the last lesson of the two parts are the teaching assessment parts[3-5].

Choice base and grade standard of teaching products

At the end of the term, students will make two teaching products. One is on-class product which is the portal site of our university. The other is out-of-class product which is personal homepage. Therefore, we put these two products as the ultimate product that to be tested. The grade standard is as followed: establishment the website is the on-class product which accounts for 1 score, making up the effect picture accounts for 3 scores and making HTML homepage accounts for 5 scores. 


\section{Implementation Effect}

The feasibility of the Evaluation System

Because is the integration of teaching, teaching is in itself with students' practice is given priority to, So completely have the ability to implement whole course evaluation; all the real integration of the Evaluation System of decomposition to each component every subproject subtasks, raised the importance of students for each class, through implementation of this scheme is feasible.

The accuracy of the evaluation

Change the disadvantages, thoroughly examining plans on the score of evaluation, more accurate, fair and just, course score, more can show the skill levels of students.

Evaluation of practical

All the real integration of the Evaluation System, itself is curriculum integration, and integration is the integration of teaching, learning, doing, take an examination of. Let enter into classroom assessment and assessment throughout. Eventually improve the quality of teaching, improve teachers' supervision[6].

\section{Conclusion}

Using project-base teaching in the Website Design isn't just a reform of teaching method; it's an entire reform for teaching. Project-based teaching was gradually launched in computer science courses of our college. Through practical experience, the students' knowledge and skills are significantly improved, the employment rate also will increase.

The website production assessment's preparation should set his center on the goal of itself. According to the content of teaching, we adjust our teaching mode and pay attention to the teaching production. We should make all-round assessment including knowledge, ability, and quality and then focus on the job capacity appraisal.

\section{References}

[1] H.B. Luo. Formulation and practice of vocational colleges curriculum assessment program [J]. The China Power Education, 2012 8(23) 36-37.

[2] Office of Academic Affairs. Guidelines for the preparation of Course examination program [M]. Liaoning Forestry Vocational and Technical College 2012.

[3] X.J Wang. Study based on the Integrated curriculum assessment program [J]. Practice and exploration, 2011 7(2) 86-88.

[4] H.F. NIU, S.Y. WANG. Research on the Appraisal Method about Class Teaching Effect [J]. Journal of Mathematics Education, 2010 4(19) 90-91.

[5] E.B. Tang. The establishment of a training course evaluation system in higher vocational colleges [J]. Science and technology in western China. 2013 1(6) 111-112.

[6] S.X. Lu. Construction of Quality Evaluation Index System for Practice Training of Higher Vocational Schools [J]. Vocational and Technical education. 2010 2(31) 59-61. 